\title{
A CIDADE VENDIDA: IMAGENS E REPRESENTAÇÕES DA VERTICALIZAÇÃO DE UBERLÂNDIA NAS PROPAGANDAS DOS MEIOS DE COMUNICAÇÃO
}

\author{
leda Carla Martins \\ Bolsista de Iniciação Científica do Dep. de Geografia - UFU \\ Beatriz Ribeiro Soares \\ Profa. Dra. do Dep. de Geografia - UFU
}

RESUMO: Este trabalho, procura analisar as tendências de produção e expansão da verticalização em Uberlândia. Para isso, analisamos a paisagem urbana, as imagens e os símbolos impressos nas propagandas dos lançamentos imobiliários verticais. Pretendemos compreender, então, como o consumo dos símbolos, do ponto de vista daqueles que os oferecem - agentes imobiliários e poder público - bem como de outros agentes sociais, resultam em transformações nas dinâmicas territoriais urbanas.

Palavras chave: cidade, verticalização, símbolos, propaganda.

\section{INTRODUÇÃO}

O presente trabalho, fruto de uma pesquisa financiada pelo Programa Institucional de Bolsas de Iniciação Científica CNPq/UFU/UFMS, tem por objetivo compreender as tendências de produção e expansão da verticalização da cidade de Uberlândia, suas imagens e representações, nos anos 90, através das imagens veiculadas pelos incorporadores imobiliários nos meios de comunicação.

Quando observamos a paisagem urbana, sua realidade é onipresente e inevitável, pois, onde quer que olhemos, percebemos seus edifícios, conjuntos residenciais, ruas e praças, shopping center, favelas, enfim, os componentes do nosso cotidiano urbano. Ela expressa os diversos momentos do desenvolvimento das relações sociais, concretizando a sociedade moderna, onde tudo é efêmero e mutável, marcado por imagens, signos e símbolos.

Nesse contexto, o processo de verticalização aparece e impõe um novo significado às representações existentes no espaço das cidades, que associado ao desenvolvimento das relações sociais e da tecnologia, possibilitou uma reprodução do espaço de forma diferenciada, ampliando as formas de representação do moderno, do novo. Uberlândia, neste contexto apresentase como um grande laboratório para pesquisas relacionadas à temática em pauta, tendo em vista que nas últimas décadas, a mesma vem passando por intensas transformações em seu conteúdo e forma, que podem ser exemplificados por seus números populacionais; seus índices econômicos; feição arquitetônica de seus edifícios; traçado urbano e de outras diferentes formas geográficas.

Assim sendo, a análise das imagens e representações da cidade, veiculadas pelos meios de comunicação, através da publicidade dos empreendimentos imobiliários verticalizados lançados na cidade nos anos 90 , poderá fornecer elementos para a compreensão dos processos de estruturação do espaço de Uberlândia.

A verticalização ocorrida em Uberlândia, teve um significado importante 
para a cidade, visto que confirmou o ideário das elites políticas locais, que idealizaram desde muito cedo, a construção de uma de cidade moderna, que demonstrasse em sua forma urbana o progresso. Desse modo, a mesma começa a verticalizar-se em meados dos anos 50, quando inicia-se, efetivamente, seu crescimento populacional, associado à implantação e diversificação de equipamentos públicos, bem como o aprimoramento das técnicas construtivas. Dessa maneira, analisar o processo de expansão vertical dessa cidade, poderá fornecer elementos que demonstrem a importância das imagens e das representações no contexto do espaço urbano, bem como os descompassos existentes entre a imagem dos lançamentos imobiliários e a representação da mesma.

\section{O PROCESSO DE VERTICALIZAÇÃO E A MODIFICAÇÃO DA PAISAGEM URBANA: ALGUMAS CONSIDERAÇÕES}

O processo de verticalização ocorre intimamente associado às transformações do uso do solo, concretizando a sociedade moderna que é marcada por imagens, signos e símbolos. E, segundo SPOSITO (1991) esses signos são vendidos, difundidos, reforçados e consumidos cada vez que se ergue na paisagem urbana mais um edifício.

Existem alguns pontos consensuais quanto ao início do processo de verticalização: um se refere ao fato de que esse é um fenômeno dos tempos modernos e outro, diz que os edifícios surgem nas áreas centrais, em que a disputa por terra urbana é muito grande, e se constitue em uma necessidade para as empresas, bem como para uma parcela da população que quer viver na área central das cidades médias e/ou grandes.

Mas o que seria a verticalização? De acordo com FERREIRA (1989) um conceito claro e simples de verticalização, seria a possibilidade de multiplicação do solo urbano através do uso do elevador. Realmente, esse processo tornou-se possível graças aos avanços das técnicas construtivas, do desenvolvimentos do cimento, do aço e como já foi mencionado, do uso do elevador. Além do mais, os edifícios são símbolos da modernidade e do progresso, mas não são conseqüência natural da urbanização, visto que são os diferentes atores sociais quem traçam a estruturação interna das cidades, levando em conta os interesses econômicos.

Assim, de acordo com SOARES e RAMIRES (1996) no contexto da cidade, transformada cotidianamente pela ação de seus usuários, estão presentes os grandes edifícios verticalizados, que se apresentam como resultado do desenvolvimento tecnológico e das conjunturas sociais.

Associado ao processo de desenvolvimento tecnológico que ocorreu nesse último século, observamos que as cidades expandiram-se, tanto em nível horizontal, facilitado graças à expansão dos meios de transporte/circulação e, verticalmente, através dos edifícios, conhecidos popularmente como arranhacéus, que modificaram substancialmente a paisagem urbana.

A construção de arranha-céus foi a expressão máxima do progresso e da autoridade, do resultado da ação transformadora do homem sobre a natureza, criando uma nova paisagem urbana, em que os grandes os edifícios se transformaram em símbolos do capitalismo. SOUZA (1994) afirma que a idéia da verticalização foi utilizada como uma solução para alguns problemas relacionados com a excessiva expansão do seu espaço físico, bem como símbolo de modernidade e cosmopolitismo.

Nas cidades brasileiras, os grandes edifícios aparecem a partir da década de 20 , inicialmente, nos grandes centros, como por 
exemplo: Rio de Janeiro e São Paulo. Em uma pesquisa desenvolvida sobre a verticalização em São Paulo, FERREIRA (1989) analisa o primeiro período desse processo, ocorrido na metrópole brasileira (1920-1939) . Nesse trabalho é destacado o papel do Estado como agente facilitador do processo de verticalização, visto que o mesmo, num primeiro momento, melhora o sistema viário, facilita a legislação urbanística. O autor constatou que nessa fase, a verticalização ocorreu no sentido de suprir a falta de espaço existente nas áreas centrais, para os escritórios, mas ainda assim foi verificado a existência de grande número de apartamento para aluguel .

Já na cidade do Rio de Janeiro, segundo VAZ (1989), ao contrário, dos processos clássicos de verticalização, o primeiro surto constituiu-se em sua maior parte de edifícios residenciais, situados fora da área central; alguns no seu entorno e outros, em bairros distantes do centro.

O processo de verticalização, nas cidades médias do interior do país começa em meados da década de 50 , após sua consolidação nos grandes centros urbanos brasileiros.

Em seus estudos sobre a cidade de Ribeirão Preto, SPOSITO (1991) define a verticalização como símbolo das cidades grandes, ou seja, modernas, arrojadas, progressivas e ricas. E levanta algumas indagações para efetivar seu trabalho.

Por que cada vez maior número de pessoas se interessava/interessa em viver numa fração menor do espaço, mesmo vivendo no interior; por que se propiciavam menor privacidade, pagando mais por isso; que níveis de satisfação de necessidades são atingidos e que tipo de símbolos são consumidos; enfim, que necessidades concretas e que desejos sublimares realizam-se neste consumo, e como se articulam o concreto e o ideológico, o consciente e o inconsciente no ato de consumir a produção imobiliária vertical. (SPOSITO 1991: 230).

Observamos que, num primeiro momento, as pessoas procuram os apartamentos em nome da vontade de isolarse, de segregar-se, em áreas centrais ou próximas do centro das cidades, garantindo, assim, um status social .Queremos destacar no trabalho de SPOSITO (1991) a análise da propaganda, como veículo de papel ideológico que consegue determinar uma demanda cada vez maior por moradias verticais.

Nota-se também que a verticalização no interior, é, contraditoriamente, expressão da necessidade de se igualar à metrópole, ao moderno.

A verticalização nas cidades do interior tem um conteúdo simbólico muito forte que passa pelo reconhecimento dos signos que a mesma contém e ideologicamente expressa: segurança, status social e comodidade.

Em Uberlândia, observamos ao longo do tempo, a idéia perpassada através do discurso da elite política aos moradores de que deve-se privilegiar o progresso, a modernidade e, igualmente, a qualidade de vida.

Nesse contexto, o processo de verticalização do espaço urbano de Uberlândia, tornou-se significativo a partir da década de 50. É preciso destacar que esta ação não se justificava, pois naquele tempo a população pequena e a topografia plana não endossavam a construção de edifícios. Observa-se, historicamente, um trabalho da elite política local em monopolizar sua visão na imprensa, reforçando sua postura ufanista, destacando aspectos favoráveis da verticalização, deixando de registrar os desfavoráveis. 
Os primeiros edifícios, com mais de cinco andares e com elevadores, que foram construídos na cidade foram Drogasil, Tubal Vilela e Romenos Simão, localizados nas avenidas João Pinheiro e Afonso Pena.

Observa-se, já nesse período, a força da propaganda como veículo capaz de convencer as pessoas à adquirirem um nova forma de morar (vide FIGURA 1).

\section{Segundo SOARES e RAMIRES} (1996), com relação à sua arquitetura, os edifícios foram construídos segundo a estética modernista, de linhas retas, cimento, aço e vidro. Quando à divisão interna, eles reproduziam a divisão das casas térreas.

O Edifício Tubal Vilela inaugurado em 1960 tornou-se símbolo de modernidade e referencial urbanístico por vários anos em Uberlândia. Ainda na década de 60 , vários outros projetos de edifícios, com mais de dez andares, foram viabilizados, não apenas para venda ou aluguel de apartamento, mas também, para uso de instituições, hotéis e serviços diversos. A TABELA 1 abaixo demonstra claramente os vários usos desses empreendimentos entre os anos de 1955/69.

Nesse período é significativo, também, o uso misto dos edifícios, em que - andar térreo e as sobrelojas eram ocupados por bancos e os demais andares eram para o uso residencial.

Como todos eles estavam localizados na área central da cidade, suas localizações propiciavam seus usos para comércio e serviços.

Até os anos 70 , o processo de incorporação foi feito por projetos acabados, ou seja, para venda ou aluguel, mas também por condomínio. A partir dos anos 80, aparecem os condomínios, em que os compradores de apartamentos e o incorporador se uniam para pagar o terreno, o projeto e a construção.

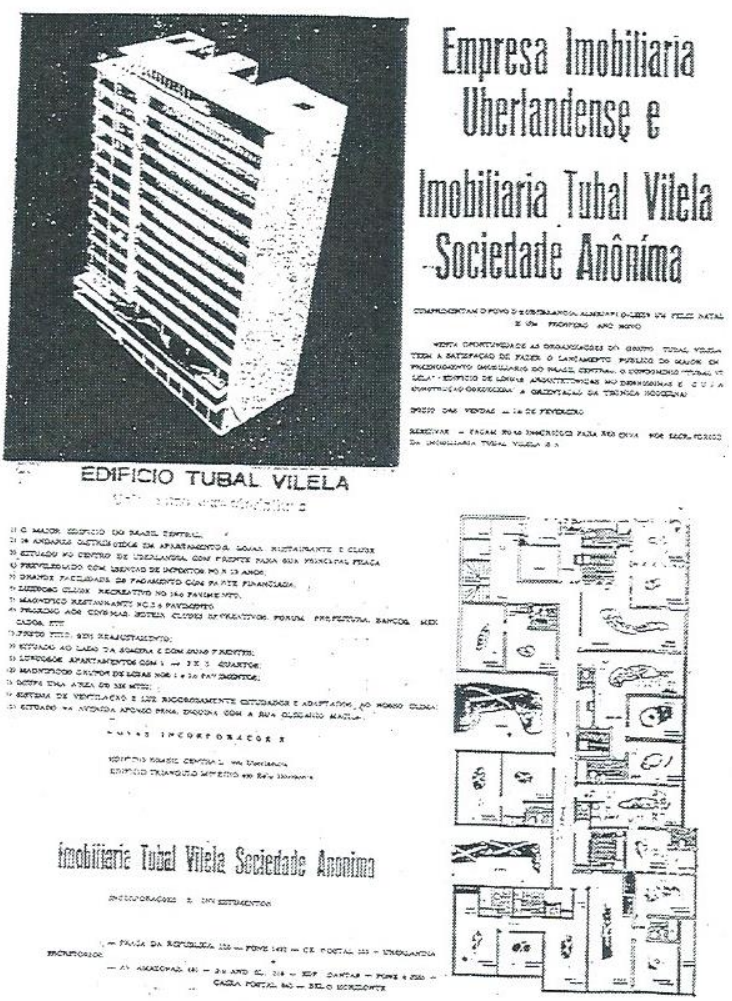

FIGURA 1: Propaganda do Edifício Tubal Vilela.

TABELA 1 - Edifícios construídos em Uberlândia - 1955/69

\begin{tabular}{lccc}
\hline $\begin{array}{l}\text { Nome do } \\
\text { Edifício }\end{array}$ & $\begin{array}{c}\text { Número de } \\
\text { Pavimentos }\end{array}$ & $\begin{array}{c}\text { Unidades } \\
\text { Residenciais }\end{array}$ \\
\hline Drogasil & 07 & 14 \\
Tubal Vilela & 16 & 112 \\
Valentina & 12 & 48 \\
Jenny Faria & 11 & 33 \\
Antônio M. Guimarães & 11 & 33 \\
Condomínio Ed. & & \\
Uberlândia & 12 & 60 salas \\
Aristides Bernardes & 12 & 48 \\
Bolivar de Carvalho & 21 & 42 \\
Banco do Brasil & 09 & - \\
Banco Com. Ind. de MG & 12 & 24 \\
Sandoval Guimarães & 22 & 44 \\
Caixa Econômica & & \\
Federal & 13 & 24 \\
Itaporã & 12 & 36 \\
Hotel Presidente & 12 & 147 aptos \\
Rosa Maria & 12 & 48 \\
Avelina Moreira & 07 & 70 salas \\
Guiomar de Freitas & 12 & 12 \\
Romenos Simão & 12 & 24 \\
Itacolomy & 14 & 45 \\
\hline FONTE: & & \\
\hline
\end{tabular}

FONTE: SOARES e RAMIRES (1996: 23) 
Ao longo do tempo, os projetos arquitetônicos dos edifícios sofreram sensíveis modificações em suas plantas, tanto interna como externamente.

Apareceram os edifícios destinados as classes de renda alta, resultando na construção de belos prédios, com apartamento de um andar inteiro, com toda a infraestrutura.

Quando aparecem no cenário urbano de Uberlândia grandes incorporadores como a Encol, Rossi Empreendimentos e Simão Construtora Ltda., percebemos um salto no número de edifícios na cidade; a análise dos lançamento imobiliários verticais dos anos 90, contém expressiva participação dos lançamentos desses empreendedores.

Pretendemos ao longo do desenvolvimento dessa pesquisa fazer uma reconstituição visual de alguns lançamento imobiliários verticais e de suas propagandas de lançamento, por hora, mostraremos apenas um lançamento da Encol (FIGURAS 2).

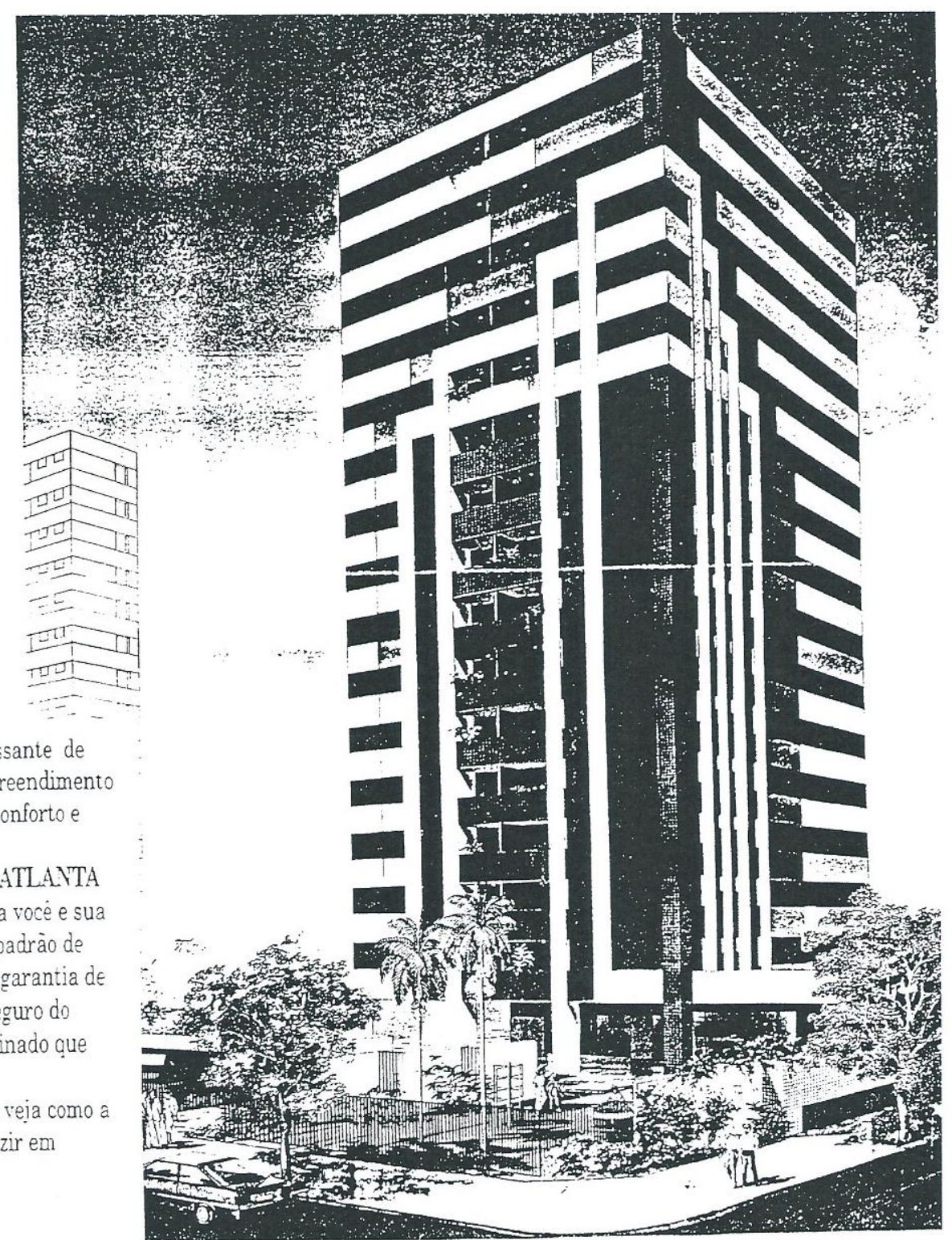

Acompanhando o desenvolvimento incessante de Lobrlândia. a ENCOL lança mais um empreendimento ie classe. trazendo uma nova traduçào de conforto e cualidade em morar bem: ATLANTA.

Localizado em ponto nobre da cidade. o ATLANTA possui espaços amplos. bem projetados para voce e sua tamilia morarem bem. E rocé ainda tem o padrào de oualidade da maior incorporadora do País, garantia de valorização rápida no investimento mais seguro do zercado. além da entrega no prazo determinado que e um dos diferenciais ENCOL.

Venha connecer de perto o ATLANTA e veja como a E.YCOL sempre pensa en voce para traduzir em esvacos. a qualidade de morar bem.

FIGURA 2: Propaganda do Edifício Atlanta - Fonte: Encol, 1993. 
A configuração territorial da verticalização em Uberlândia pode ser bem compreendida pelo trabalho de SOARES (1995) pois a autora nos dá uma visão da distribuição dos edifícios com mais de cinco andares no espaço dessa cidade (vide FIGURA 3).

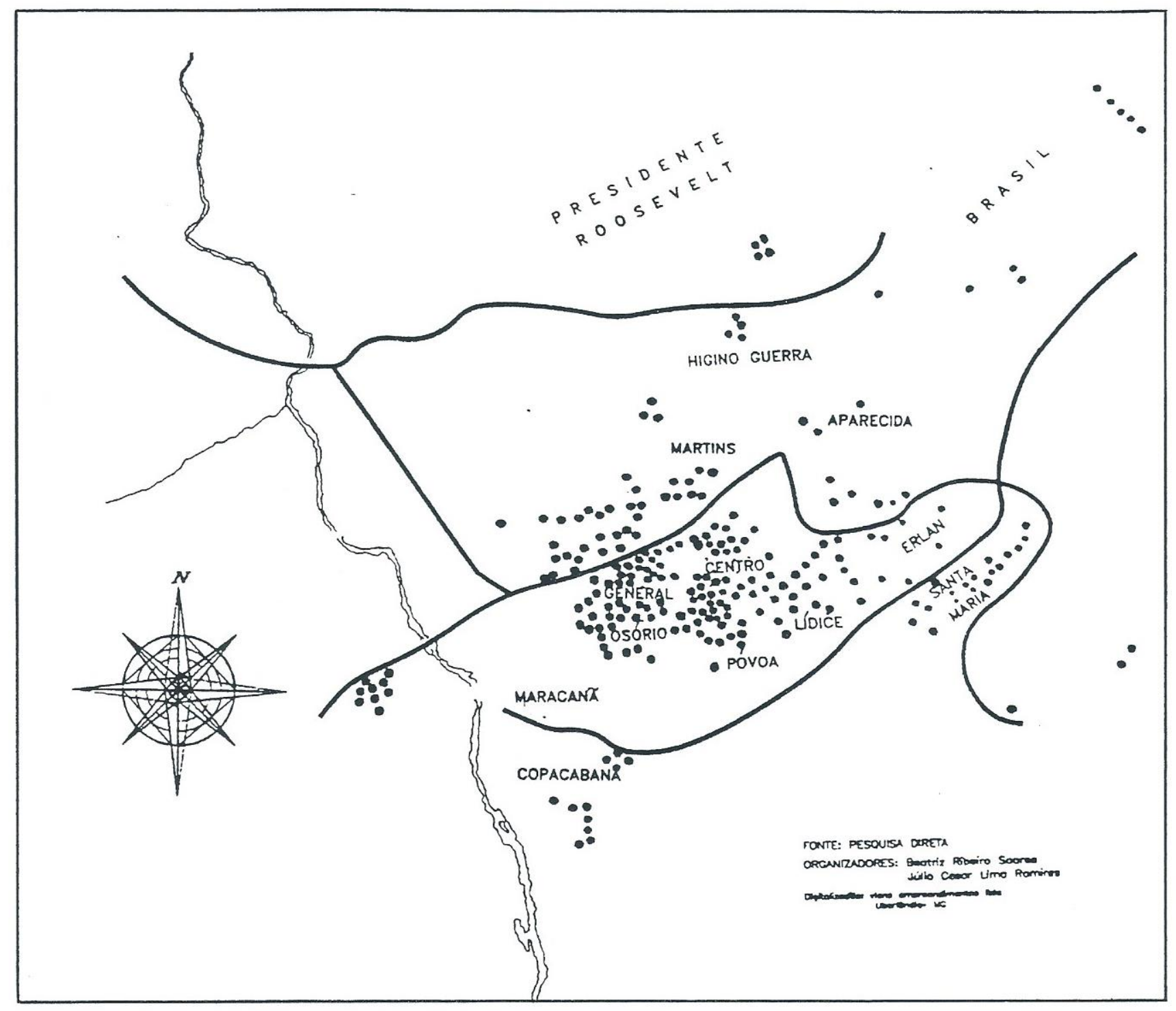

FIGURA 3: Uberlândia: Distribuição espacial dos edifícios com mais de 5 (cinco) pavimentos - 1955/1994.

Observa-se nessa figura que os lançamento imobiliários verticais concentravam-se preferencialmente no núcleo central, todavia a partir dos anos 80 esse processo se espraia pelos bairros: Martins, Copacabana, Santa Mônica, Roosevelt, Jaraguá, Lídice, Santa Maria e Brasil.A verticalização na cidade vem acentuando-se ao longo desses últimos 40 anos, confirmando o ideário de modernização e de progresso impostos pelas elites políticas e pelos veículos de propaganda de lançamentos imobiliários, introjetando nas pessoas o desejo de adquirir essa nova maneira de morar na cidade. 


\section{AS ESTRATÉGIAS DE VENDA DOS IMÓVEIS: UMA ANÁLISE PRELIMINAR}

Para atingirmos o objetivo de compreender o processo de verticalização na cidade de Uberlândia, através das imagens veiculadas pelos incorporadores imobiliários nos meios de comunicação, pelas propagandas dos lançamentos, nos anos 90 , fizemos um levantamento nos sete principais agentes incorporadores - Encol, Construtora Simão Ltda., Minas Goiás, Fonseca e Freitas, RF Empreendimentos Imobiliários, CCO Empreendimentos e Eldorado Minas Construtora - especializados na produção de edifícios de Uberlândia. Para fazermos sua análise, consideramos em cada folheto de propaganda: o nome do empreendimento; sua localização; tipo de elementos geográficos existentes; sua linguagem; elementos simbólicos; aspectos econômicos e equipamentos coletivos existentes.

A análise desses itens mostram que na organização do espaço urbano, devemos levar em conta que o uso da cidade se faz como mercadoria e que essa organização está impregnada de ideologia. Assim, o próprio nome do edifício já procura atrair os compradores. A localização também aparece ligada a ótimos argumentos ideológicos, atribuindo tranqüilidade, segurança e uma série de vantagens existentes na área escolhida.

Outro ponto relevante é o que considera os equipamentos presente nos empreendimentos, tais como: piscina, play ground, quadras poliesportivas, salão de festas entre outros. Estes, conferem um símbolo de status e leva à exposição do luxo e do conforto de se morar em edifícios. Relacionamos no quadro abaixo, apenas como exemplo, os lançamentos de edifícios da RF Empreendimentos Imobiliários:

A RF Empreendimentos Imobiliários atua em Uberlândia desde 1979 e realizou quatro lançamentos imobiliários verticais nesse período: Residencial Pinheiros, Varandas do Praia, Edifício Clarinda de Freitas, Edifício Cristiane Residence. Desses empreendimentos, um tem uma área construída de $52 \mathrm{~m}^{2}$, com apenas um quarto; e o segundo possui dois quartos e área construída de $55 \mathrm{~m}^{2}$; e com três quartos existem dois empreendimentos um com área construída de $73 \mathrm{~m}^{2}$ e o outro com $122 \mathrm{~m}^{2}$.

Quando lança no mercado um empreendimento, a empresa traça uma estratégia de venda, prevê o público alvo e o veículo certo para alcançá-lo, e gasta aproximadamente $5 \%$ do total da obra para a divulgação do lançamento. Para atingir o público, a mesma procura agências de publicidade especializadas para elaboração do material.

Para conhecermos essa dinâmica, realizamos algumas entrevistas junto as agências de publicidade e propaganda - ZR Publicidade e Propaganda e Gann Publicidade, que apresentaram resultados que demonstram que o agente imobiliário e/ ou a construtora, quando procuram os serviços das agências pela primeira vez, levam definidos: o local, o projeto do empreendimento, e o nome. Posteriormente, a sua equipe organiza $\circ$ aparato de divulgação do lançamento imobiliário, dependendo do porte do empreendimento são usados vários caminhos de divulgação de maneira simultânea: televisão, rádio, jornal, folhetos e out-doors. 
QUADRO 1 - Uberlândia: propagandas de lançamentos de edifícios - 1990

\begin{tabular}{|c|c|c|c|c|c|c|}
\hline \multicolumn{7}{|c|}{ RF EMPREENDIMENTOS IMOBILIÁRIOS LTDA. } \\
\hline $\begin{array}{l}\text { Nome do } \\
\text { Edifício }\end{array}$ & Localização & $\begin{array}{c}\text { Elementos } \\
\text { Geográficos }\end{array}$ & Linguagem & $\begin{array}{l}\text { Elementos } \\
\text { Simbólicos }\end{array}$ & $\begin{array}{c}\text { Aspectos } \\
\text { Econômicos }\end{array}$ & Equipamento \\
\hline $\begin{array}{c}\text { Clarinda } \\
\text { de Freitas }\end{array}$ & $\begin{array}{l}\text { R. Felisberto } \\
\text { Carrijo com } \\
\text { Bernardo } \\
\text { Guimarães }\end{array}$ & $\begin{array}{l}1 \text { mapa de } \\
\text { localização }\end{array}$ & $\begin{array}{l}\text { "Não é } \\
\text { todo dia } \\
\text { que você } \\
\text { tem um } \\
\text { projeto } \\
\text { como } \\
\text { este". }\end{array}$ & $\begin{array}{c}\text { Pça } \\
\text { Clarimundo } \\
\text { Carneiro e } \\
\text { Pça Adolfo } \\
\text { Fonseca }\end{array}$ & & $\begin{array}{c}\text { Quadra } \\
\text { Poliesportiva, } \\
\text { salão de } \\
\text { festas e } \\
\text { guarita de } \\
\text { segurança. }\end{array}$ \\
\hline $\begin{array}{c}\text { Cristiane } \\
\text { Residence }\end{array}$ & $\begin{array}{l}\text { Av. Cesário } \\
\text { Alvim } 160\end{array}$ & & & & $\begin{array}{c}100 \\
\text { parcelas } \\
\text { para pagar }\end{array}$ & $\begin{array}{c}\text { Portões } \\
\text { eletrônicos e } \\
\text { interfones, } \\
\text { antena } \\
\text { coletiva e } \\
\text { seguro de } \\
\text { vida. }\end{array}$ \\
\hline $\begin{array}{c}\text { Resid. } \\
\text { Pinheiros }\end{array}$ & $\begin{array}{c}\text { Av. } \\
\text { Engenheiro } \\
\text { Azeli com Av. } \\
\text { Paulo Roberto } \\
\text { C. Santos }\end{array}$ & $\begin{array}{l}1 \text { mapa de } \\
\text { localização }\end{array}$ & $\begin{array}{l}\text { "Comece o } \\
\text { ano bem, } \\
\text { seja pro- } \\
\text { prietário } \\
\text { de um } \\
\text { aparta- } \\
\text { mento bem } \\
\text { projetado e } \\
\text { fácil de } \\
\text { pagar". }\end{array}$ & Rodoviária & $\begin{array}{l}\text { A partir de } \\
2,4 \text { salários } \\
\text { mínimos }\end{array}$ & $\begin{array}{c}\text { Quadra } \\
\text { poliesportiva } \\
\text { e play-ground }\end{array}$ \\
\hline $\begin{array}{c}\text { Cond. } \\
\text { Varandas } \\
\text { do Praia }\end{array}$ & $\begin{array}{c}\text { Av. Rondon } \\
\text { Pacheco com } \\
\text { Av. dos } \\
\text { Municípios }\end{array}$ & $\begin{array}{c}1 \text { mapa de } \\
\text { localização }\end{array}$ & $\begin{array}{l}\text { Melhor } \\
\text { aproveita- } \\
\text { mento de } \\
\text { espaço por } \\
\text { metro }\end{array}$ & Praia Clube & & $\begin{array}{l}\text { Elevador e } \\
\text { interfone. }\end{array}$ \\
\hline
\end{tabular}

Segundo os entrevistados embora seja muito discutido os resultados obtidos através das divulgações realizadas pelas agências, as mesmas não possuem estatísticas que os quantifiquem, as mesmas podem ser feitas pelo empreendedor. $O$ certo é que - melhor veículo de divulgação, segundo os entrevistados, em Uberlândia, é a televisão.

A Gann Publicidade e Propaganda, empresa que realiza trabalhos para a Encol, e para Rossi em Uberlândia e Uberaba, define algumas particularidades no trabalho de divulgação dos lançamentos imobiliários. Por exemplo: não usam maquetes, dizem que essa parece ser uma prática em vias de extinção, pois consideram o trabalho desenvolvido através da televisão e do uso da realidade virtual, muito mais atrativo. Copiam a mesma propaganda feita pela Rossi em São Paulo; pois esclarecem que a maioria dos lançamentos dessa empresa possuem os mesmos nomes, assim só mudam o endereço do empreendimento, enquanto, o trabalho de arte, imagens, cores etc.. permanecem os mesmos. Este é o caso do lançamento dos edifícios Villaggio di Roma, Villaggio di Siena e Villaggio di Capri, em Uberlândia.

Segundo informações obtidas na agência Gann, o empreendedor imobiliário utiliza $3 \%$ do total gasto na obra para divulgação, através dos diferentes veículos da mídia, que pode ser considerado pouco, nos lançamentos feitos em uma cidade do porte de Uberlândia, mas se levarmos em conta os gastos com construções em uma cidade como São Paulo, veremos que essa porcentagem é suficiente para garantir um bom retorno em vendas.

A absorção desse produto urbano - o edifício - por meio da propaganda, está 
associada ao mito da cidade moderna e isso demonstra uma face marcante da contemporaneidade, onde o controle da informação constitui-se em fundamental estratégia de poder e dominação.

A reflexão à cerca dessas tendências, verticalização e propaganda, possibilitará estabelecer uma ligação entre o simbólico e os processos de (re)estruturação da cidade.

\section{REFERÊNCIAS BIBLIOGRÁFICAS}

CORRÊA, R. L. A dimensão cultural do espaço: alguns temas. Espaço e Cultura. ano I, p. 1-21, out, 1995. 1989.

O espaço urbano. São Paulo: Ática,

DEL RIO, V.; OLIVEIRA, L. (org.). Percepção ambiental: a experiência brasileira. São Paulo: Estúdio Nobel, p. 83-96, 1996.

FERREIRA, N. S. M. A (des) verticalização de São Paulo. São Paulo: FAU-USP, 1987. (Dissertação, Mestrado).

São Paulo imobiliário: sobre a origem do arranha-céu (1929-1939). III Encontro Nacional da ANPUR, Águas de São Pedro: 1989, vol. 1, p. 189-197.

A cidade vertical e o urbanismo moderno: São Paulo 1920-1939. São Paulo: FAU/USP, 1994. (Tese, Doutorado).

FISHER, S. Edifícios altos no Brasil. Espaço \& Debates. São Paulo: NERU, ano 14, no 37, p. 61-67, 1994.

LEMOS, A. I. G. As transformações da metrópole paulistana nos anos 80 . Revista do Departamento de Geografia. São Paulo: ano 6, p. 113-118, 1992.

MENDES, C. M. O edifício no jardim: um plano destruído. A verticalização de
Maringá. São Paulo: FFLCH/USP, 1992. (Tese, Doutorado).

SALGADO, I. Caracterização dos promotores imobiliários que atuam na cidade de São Paulo (1977-1982). Espaço \& Debates. São Paulo: NERU, ano 8, no 1, p. 51-71, 1987.

SILVEIRA, G. L. R. Incorporadores de porte médio: contribuição ao estudo da produção imobiliária no Rio de Janeiro. Rio de Janeiro: IPPUR/UFRJ, 1990. (Dissertação, Mestrado).

SOARES, Beatriz R. Habitação e produção do espaço urbano de Uberlândia. São Paulo: FFLCH/ USP, 1988. (Dissertação, Mestrado).

Uberlândia: anotações sobre seu crescimento urbano. Cadernos de História, Uberlândia: EDUFU, 4(4): 4962, jan. 1993.

Uberlândia: Da Cidade Jardim ao Portal do Cerrado - Imagens e representações no Triângulo Mineiro. Tese de Doutorado, São Paulo: FFLCH/ USP, 1995.

- e RAMIRES, Júlio C. L. As transformações do centro de Uberlândia no contexto de expansão da cidade. Sociedade \& Natureza, Uberlândia: EDUFU, 5(9 e 10): 25-38, jan./dez. 1993.

SOUZA, Maria A. A. de. A identidade da metrópole: A verticalização em São Paulo. São Paulo: HUCITEC/EDUSP, 1994.

SPOSITO, Maria E. V. O chão arranha o céu: a lógica da (re)produção da cidade. Tese de Doutorado, São Paulo: FFLCH/USP, 1991.

O chão em Presidente Prudente: A lógica da expansão territorial urbana. 
Rio Claro: IGCE/UNESP, 1983. (Dissertação, Mestrado).

VAZ, L. F. Particularidades do processo inicial de verticalização na cidade do Rio de Janeiro. Encontro Nacional da ANPUR, 3, Águas de São Pedro, 1989. Anais. Águas de São Pedro, 1989. 